\title{
Highly oxygenated guaianolides from some compositae plants
}

\author{
Vivek Krishna, Pradeep K. Gupta, Sonakshi Jain and Pahup Singh* \\ Department of Chemistry, University of Rajasthan, Jaipur-302 004, India
}

Manuscript received 21 September 2001

\begin{abstract}
The isolation of twenty new highly oxygenated guaianolides along with several known guaianolides from Vernonia arkansana (aerial parts and roots), Pseudostifftia kingii (acrial parts), Dicoma anomala (roots), Hypochoeris cretensis, Saussurea salicifolia, S. involucrata, S. candicans, Bishopanthus soliceps and Blainvillea latifolia (aerial parts) have been reviewed.
\end{abstract}

The sesquiterpene lactones are characteristic secondary metabolites of Compositae and their biological activities also make them of interest to pharmacologists. These lactones are formed by intramolecular cyclization of $\gamma$ - or $\delta$ hydroxy acids and broadly termed as cyclic esters. The suffix 'olide' in their names refers to the lactone moiety in the molecule. The $\alpha, \beta$-unsaturated- $\gamma$-lactones are $c i s$ - or transfused to the $\mathrm{C}_{6}-\mathrm{C}_{7}$ or $\mathrm{C}_{8}-\mathrm{C}_{7}$ positions of the carbocyclic skeleton. The structural variation of the basic sesquiterpene skeleton involves the incorporation of an epoxy ring, hydroxy groups, ester moieties and reduction or oxidation of certain groups or even opening of the rings. Acids generally involve in esterification are 4 and/or 5 carbon acids, viz. methacrylic, angelic, tiglic, senecioic, methylbutyric acids or their hydroxy and/or acetoxy derivatives. Guaianolides are derived from guaiane skeleton. In this short review, we present the results of structure elucidation of two guaianolides from Vernonia arkansana' ${ }^{\prime}$, the senecioate and the hydroxysenecioate guaianolides from Psendostiffica king $i i^{2}$, a $9 \alpha$-hydroxyguaianolide from Dicoma anomala sub sp. cirsioides ${ }^{3}$, a guaian-5,12-olide along with its precursor from Hypochoeris cretensis ${ }^{4}$, four $11 \alpha$-13-dihydro derivatives from Saussurea salicifolia ${ }^{5}$ L., an $8 \alpha$-propionyloxydehydrocostus lactone from $S$, involucrata ${ }^{5}$, three chlorojanerin derivatives from $S$. candicans ${ }^{6}$, five highly oxygenated guaianolides from Bishopanthus soliceps ${ }^{7}$ and a pumilin derivative from Blainvillea latifolia ${ }^{8}$.

Vernonia arkansana DC has been investigated earlier ${ }^{9,10}$. The re-investigation of roots afforded the known guaianolides 1-6 ${ }^{11}$ along with a new one 7 . The structure of 7 was clearly arrived from the ${ }^{1} H$ NMR spectral data which were similar to that of dehy drozaluzanin C 5 . The stereochemistry of $\mathrm{C}-8$ was deduced from couplings observed for H-S and from the typical downtich shifi of $11-13^{\prime}$ proton. Its molecular formula $\mathrm{C}_{15} \mathrm{H}_{16}()_{4}$ was established from high resolution mass spectrometry and identified as $8 \alpha$ hydroxydehydrozaluzanin $\mathrm{C}$. The aerial parts on chemical

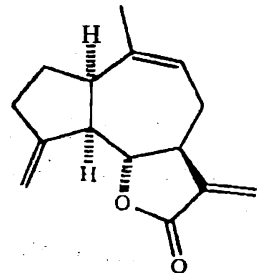

1

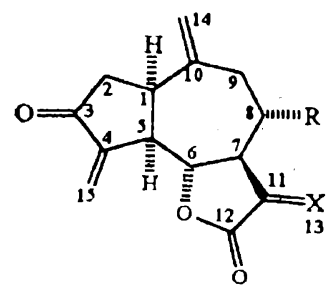

$5 \mathrm{X}=\mathrm{CH}_{2}, \mathrm{R}=\mathrm{H}$

$6 \mathrm{X}=\mathrm{H}, \alpha \mathrm{Me}, \mathrm{R}=\mathrm{OH}$

$7 \mathrm{X}=\mathrm{CH}_{2}, \mathrm{R}=\mathrm{OH}$

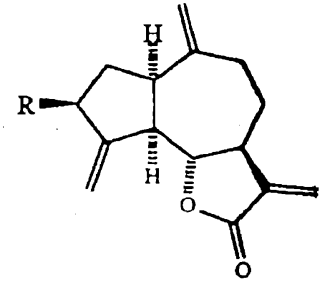

$2 \mathrm{R}=\mathrm{H}$

$3 \mathrm{R}=\mathrm{OSen}$

$4 \mathrm{R}=\mathrm{OH}$

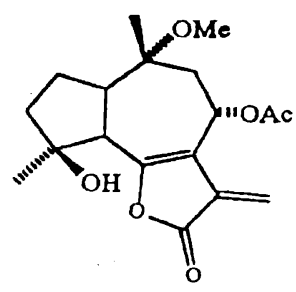

8 examination gave marginatin, three bourbonenolides and a new methoxyguaianolide 8. Its 'II NMR data agree with its structure. From the signals of $\mathrm{H}-13$, the presence of a methylene lactone was contimed. However, the absence of signals for H-6, H-7 indicated a 6,7-double bond, its presence being supported by a downfield shifted doublet at $\delta 2.86$, which was coupled with a brouiened double doublet at $\delta$ 2.26. These signals probably were those of $11-1$ and $11-5$. A methoxy group was present al $C-10$ and an acetoxy group at C-8 position. The tereochemistry at $\mathrm{C}-4$ and $\mathrm{C}-10$ was assigned by analogy to that of bourbonenolides and character-

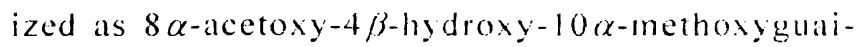
6.7.11(13)-diene-6.12-olide. Probably lactone could be formed by fragmentation of bourbonenolide 9 by allach of methanol at $\mathrm{C}-10$ as shown in Scheme 1 . The bourbonenolide 9 has simultaneously been isolated from this plant. 


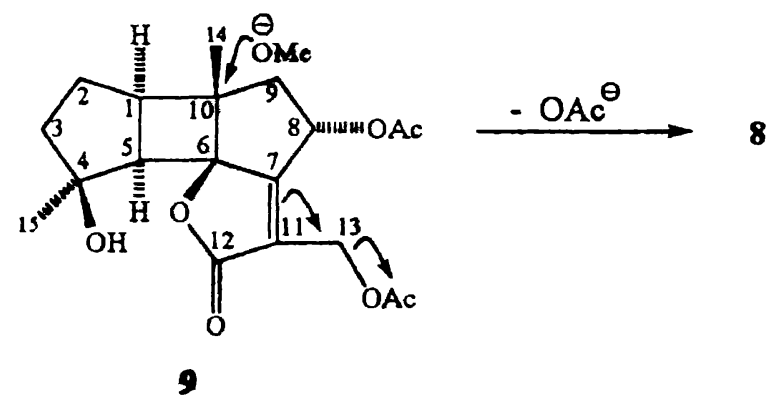

Scheme 1

Pseudostifftia is a monotypic genus and belongs to the subtribe Pseudostifftinae ${ }^{12}$. Earlier work on Pseudostifftia kingii $\mathrm{H}$. Robins led to the isolation of acetylenes and triterpenes ${ }^{13}$. The re-investigation of its aerial parts reported the isolation of known guaianolides, viz. desacylcynaropicrin $10^{14}$, arguerin B $11^{15}$, cynaropicrin $12^{16}, 8 \alpha$-hydroxydehydrozaluzanin $\mathrm{C}^{1}$, the corresponding $11 \beta, 13$-dihydroderivative $6^{1}$, as well as two further lactones, the senecioate 13 and the hydroxysenecioate 15 .
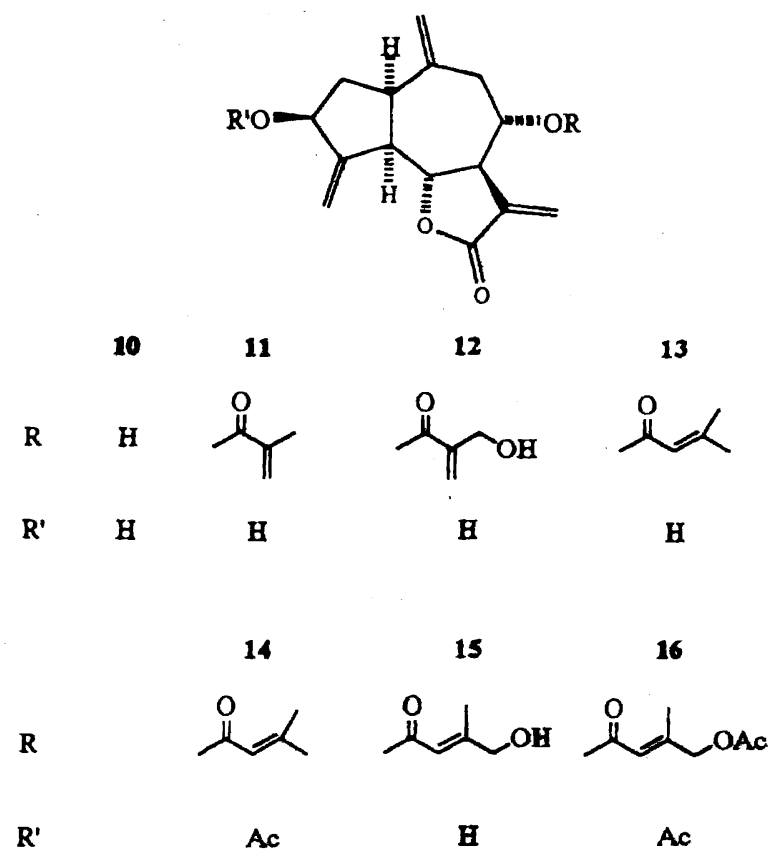

The structure of 13 was established from ${ }^{1} \mathrm{H}$ NMR data. Its NMR clearly showed the presence of a zaluzanin $\mathrm{C}$ derivative, as most signals were similar to those of zaluzanin C. However, an additional senecioyloxy residue was present. Spin decoupling showed that this group had to be placed at C-8 while from the coupling constants the $\alpha$-orientation could be established. Acetylation afforded the acetate $\mathbf{1 4}$ and 13 was identified as $8 \alpha$-senecioyloxydehydrozaluzanin C. The ${ }^{1} H$ NMR spectral data of $\mathbf{1 5}$ indicated that a hy- droxylated ester group was present. Since the signal of the olefinic methyl group was at $\delta 2.15$, the stereochemistry. was also clear. All other signals were similar to those of $\mathbf{1 3}$. Acetylation gave the diacetate $\mathbf{1 6}$ and its ${ }^{1} \mathrm{H}$ NMR spectrum further established the structure. 15 was named as $8 \alpha$ (4' -hydroxysenecioyloxy)dehydrozaluzanin C.

So far the results of chemical investigation of Dicoma species indicated the presence of characteristic oxygenated germacranolides ${ }^{17,18}$. A re-investigation of the roots of Dicoma anomala Sond. subsp. cirsiodes (Harv.) Willd. afforded in addition to stigmasterol, sitosterol, lupenone, eudesmanolides, a known guaianolide(dehydrozaluzanin $C$ ) 5 and a new guaianolide 17.

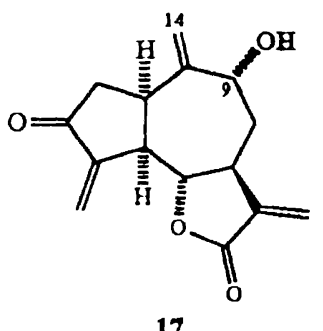

The ${ }^{1} \mathrm{H}$ NMR spectrum of 17 was very similar to 5 . The presence of a $9 \alpha$-hydroxy group was deduced from the downfield shifts of $\mathrm{H}-14$ (5.09 s, $4.67 \mathrm{~d})$ and $\mathrm{H}-9$ (4.63 ddd) and the value of coupling $J_{8,9}$. This was confirmed by spin decoupling which allowed the assignment of all signals. The corresponding 9-O-angelate was isolated from Zinnia species ${ }^{19}$ and as expected the couplings $J_{8.9}$ were nearly the same. It was characterized as $9 \alpha$-hydroxydehydrozaluzanin C.

Earlier work on the genus Hypochoeris has shown that guaianolides related to lactucin may be characteristic for this genus ${ }^{20-22}$. The chemical examination of the aerial parts of Hypochoeris cretensis Benth. showed the presence of taraxasterol, lupeol and its acetate, phytol, isoalantolactone and a new guaian-5,12-olide 18 and the corresponding precursor 19.

The structure of 18, which on addition of diazomethane afforded the pyrazoline $\mathbf{2 0}$, was derived from the molecular formula and the high field ${ }^{1} \mathrm{H}$ NMR spectrum.

The presence of a methylene lactone followed from the typical pair of downfield signals at $\delta 6.62$ and 5.71. The IR band at $1740 \mathrm{~cm}^{-1}$ indicated a $\delta$-lactone. The chemical shifts of two olefinic methyls and a quartet at $\delta 6.18$ showed that most likely a guaianolide with a keto group at $\mathrm{C}-2$ and a $1(10)$ as well as a 3,4-double bonds were present. The absence of a H-5 signal and the results of spin decoupling clearly showed that a 5,12-guaianolide was present, which 
Krishna et al. : Highly oxygenated guaianolides from some compositae plants

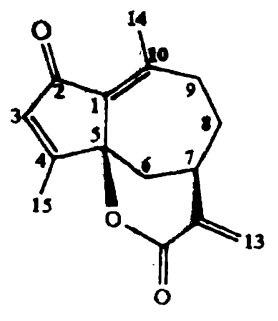

18

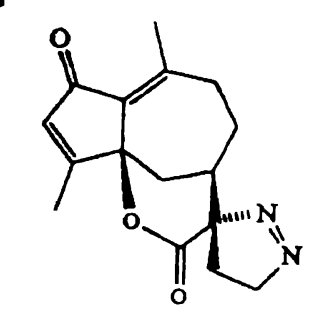

20

required an equatorial orientation of $\mathrm{H}-7$. Accordingly, this signal was narrowly split only as all. couplings were small. Inspection of a model further showed that the angles H-7$\mathrm{H}-13$ supported the observed small couplings of $\mathrm{H}-13$. The stereochemistry of the pyrazoline derivative $\mathbf{2 0}$ was deduced from the observed downfield shift of $\mathrm{H}-6 \beta$. The ${ }^{1} \mathrm{H}$ NMR spectral data of 19 showed that a methyl ester was present. The conformation was clearly different from that of $\mathbf{1 8}$ since H-7 was now axial as followed from the couplings observed. Spin decoupling allowed the assignment of all signals. Guaian-5,12-olide 18 was named as hypocretenolide and its precursor 19 as methyl hypocretenoate.

The large genus Saussurea (Compositae, tribe-cynareae) with more than 300 species ${ }^{23}$ has been investigated chemically for acetylenes ${ }^{24}$ as well as for sesquiterpene lactones. So far lactones are reported from nine species ${ }^{25-32}$. Guaianolides related to cynaropicrin 12 are characteristic of this genus. Some other types of lactones were also reported from S. lappa ${ }^{26}$. Three species, namely, S. salicifolia, $S$. involucrata and $S$. candicans have been examined. The aerial parts of $S$. salicifolia (L.) DC. gave arctigenin, matairesinol, trachelogenin, cynaropicrin 12, 19-desoxyjanerin 21 , janerin 22 , desacyl-janerin- $O$-hydroxytiglate $\mathbf{2 3}$, desacyljanerin 24 and $11 \alpha, 13$-dihydro derivatives 25-28.

The polarity of lactones $\mathbf{2 5 - 2 8}$ was very similar, hence their separation was difficult. These could only be separated by TLC and HPLC.

The structures of $\mathbf{2 5}$ and $\mathbf{2 7}$ were followed from the ${ }^{1} \mathrm{H}$ NMR spectra which indicated that these compounds only differed in the nature of the ester groups. The typical exomethylene signals in the spectrum of cynaropicrin were replaced by a methyl doublet at $\delta 1.13$ and a doublet quartet
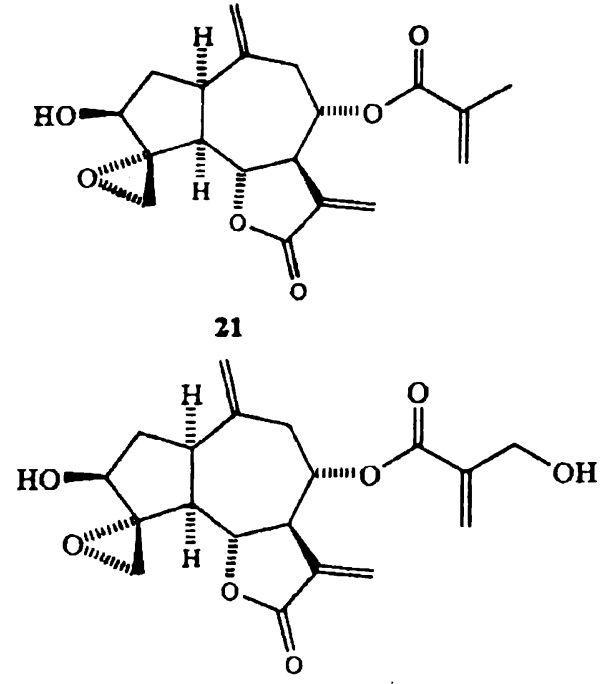

22<smiles>C=C1C(=O)O[C@H]2[C@@H]1[C@@H](OC(=O)/C(C)=C/CO)CC(=C)[C@H]1C[C@H](O)[C@]3(CO3)[C@H]12</smiles>

23

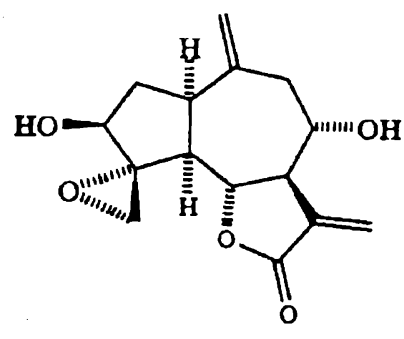

24

at $\delta 2.77$. Accordingly, these lactones were 11,13-dihydro derivatives of cynaropicrin and of the corresponding 4hydroxytiglate. The configuration at $\mathrm{C}-\mathrm{l} 1 \mathrm{l}$ was followed from the coupling $J_{7,11}(7 \mathrm{~Hz})$, while a very similar compound with a $11 \alpha$-methyl showed as usual a large coupling ${ }^{25}$. The ${ }^{1}$ H NMR spectral data of $\mathbf{2 6}$ and 28 were similar to that of janerin, the $4 \beta, 15$-epoxide of cynaropicrin ${ }^{33}$ and with that of the corresponding 4-hydroxytiglate ${ }^{34}$, respectively. However, again the signals of the exomethylene group ( $\mathrm{H}-13)$ were replaced by a methyl doublet at $\delta 1.14$ and a doublet quartet at 2.74. Subsequently, these lactones were 11,13dihydro derivatives of the previously isolated methylene lactones. Again the coupling $J_{7,11}$ exhibited the presence of $11 \beta$-methyl groups. The lactones $\mathbf{2 6}$ and $\mathbf{2 8}$ were identified as $11 \alpha, 13$-dihydrojanerin and $11 \alpha, 13$-dihydrodesacyljanerin-4-hydroxytiglate, respectively. 
<smiles>[2H][C@H]1C(=O)O[C@H]2[C@H]1[C@@H](OC(=O)C(=C)CO)CC(=C)[C@]1(C)CC(OC)C(=C)[C@@]21C</smiles>

25<smiles>C=C1C[C@@H](OC(=O)C(=C)CO)[C@@H]2[C@H]([C@H]3C[C@H](O)[C@]4(CO4)[C@H]3C)C(=O)O[C@@H]2C1</smiles><smiles>C=C1C[C@H](OC(=O)/C(C)=C/CO)[C@@H]2CC(=O)O[C@H]2[C@H](C)C1</smiles><smiles>[CH][C@@H]1C(=O)O[C@H]2[C@@H]1[C@@H](OC(=O)/C(C)=C/CO)CC(=C)[C@H]1C[C@H](O)[C@]3(CO3)[C@@H]12</smiles>

28

Saussurea involucrata (Kar. et kir.) Sch. Bip. is used in the folks medicine by Mangolians and it is said to have activities similar to Ginseng. On examination it afforded costic acid, dehydrocostus lactone 2 , its $11 \beta, 13$-dihydro derivative 29, $8 \alpha$-hydroxydehydrocostus lactone 30 , its acetate 31 and the corresponding propionate 32 as new guaianolide.

The structure of propionate $\mathbf{3 2}$ could be easily deduced from the ${ }^{1}$ H NMR spectrum which was very close to that of the corresponding acetate ${ }^{35} 31$. The acetate signal of the latter was replaced by a triplet and a quartet at $\delta 1.17$ and 2.41 , respectively, and named as $8 \alpha$-propionyloxydehydrocostus lactone.

Previous work on Saussurea candicans C. B. Clarke led to the isolation of acetylenes ${ }^{24}$. The aerial part of this plant on re-investigation gave arctigenin and matairesinol, cynaropicrin 12, desacylcynaropicrin 10, aguerin-B 11, janerin 22, 19-desoxychlorojanerin 33, chlorojanerin 34.

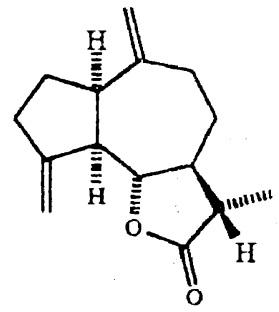

29

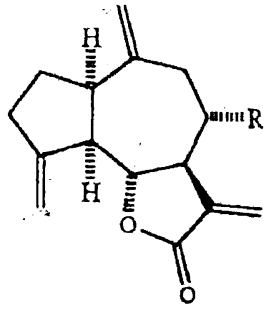

$30 \mathrm{R}=\mathrm{OH}$

$31 \mathrm{R}=\mathrm{OAC}$

$32 \mathrm{R}=\mathrm{OCOEt}$ centaurepensin 35 , repdiolide triol 36 in addition to tetrol 37, its 15-methoxy 38 and 15 -acetoxy 39 derivatives.

The polarity of lactones $37-39$ was very high and therefore their separation could be achieved by repeated preparative TLC and HPLC. The structure of 37 was established<smiles></smiles>

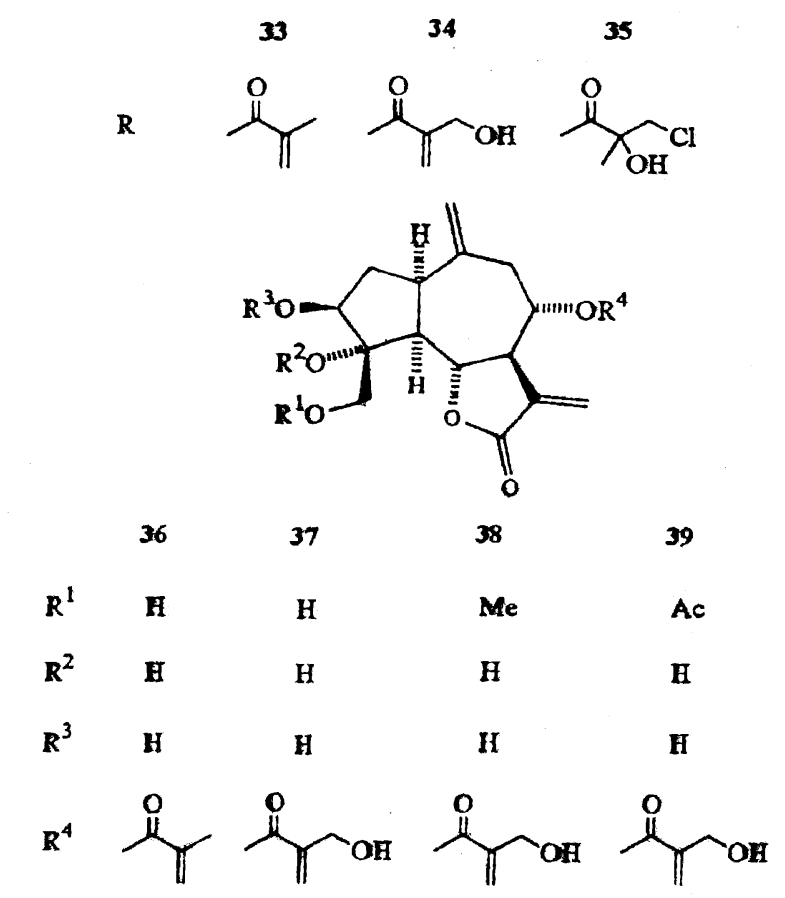

from ${ }^{\text {H }}$ NMR spectral data which revealed that this compound differed from repdiolide triol $\mathbf{3 6}$ in the nature of the ester moiety at C-8 position. Methyl acrylate signals were replaced by its 3 -hydroxy derivative and subsequently methyl signal was replaced by a broad singlet at $\delta 4.39$ inte- 
Krishna et al. : Highly oxygenated guaianolides from some compositae plants

grated for two protons. The chemical shifts of the other protons remained unaltered. A similar compound with a 4hydroxytiglate ester function at C-8 was reported from $C e n-$ taurea imperialis ${ }^{36}$. On acetylation it gave two tetracetates 40 and $\mathbf{4 1}$.

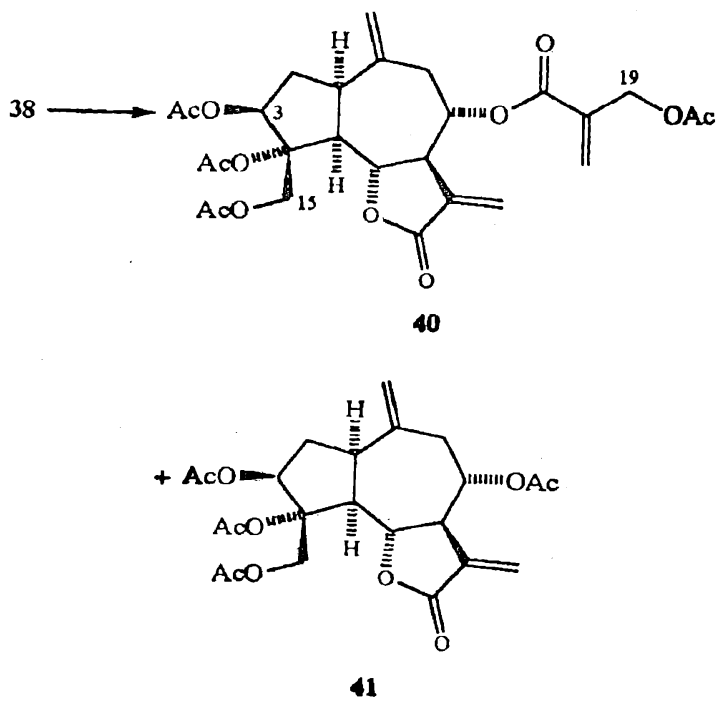

In the former case all the four hydroxyl groups acetylated and consequently $\mathrm{H}-3, \mathrm{H}-15, \mathrm{H}-19$ were shifted downfield. In the latter case (41), 3-hydroxymethacrylate ester group hydrolyzed prior to acetylation and signals of methacrylate ester function ( $\delta 6.33 \mathrm{~s}, 5.97 \mathrm{q}, 4.39 \mathrm{~s} \mathrm{br})$ replaced by an acetate singlet at $\delta 2.19$. The ${ }^{1} \mathrm{H}$ NMR spectral data of 38 and 39 were very similar to that of repdiolide triol 36 with additional peaks for a methoxy $(\delta 3.45)$ and an acetoxy ( $\delta 2.18)$ functions, respectively. The $\mathrm{H}-15, \mathrm{H}-15^{\prime}$ doublets were shifted slightly upfield at $\delta 3.98$ and 3.67 in former and shifted downtield at $\delta 5.03$ and 4.22 in the latter case. Chemical shifts of the rest of protons of both the lactones remain unchanged. The lactones 37-39 were named as 15deschloro-15-hydroxychlorojanerin, 15-deschloro-15methoxychlorojanerin and 15-deschloro-15-acetoxychlorojanerin, respectively.

Bishopanthus soliceps is a member of a new monotypic genus of the tribe Liabeae of family Compositae ${ }^{37}$. No work has been reported on this species. The aerial parts of $B$. soliceps afforded ferulic acid, the flavones pectolinarigenin, 3-desmethoxycentaureidin and eupatolitin, the guaianolides anhydrocumambrin A, 1-desoxy-1 $\alpha$-peroxyrupicolin $A$ and

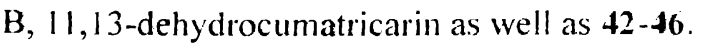

The 'H NMR spectral data showed $\mathbf{4 2}$ and $\mathbf{4 3}$ were hydroperoxides ( $\mathrm{s}$ br $8.38,8.47$ respectively). A pair of doublets at $\delta 6.22$ and 6.34 in the spectrum of 42 with a $6 \mathrm{~Hz}$ coupling clearly revealed that a guaianolide with a $2.3 \ldots$

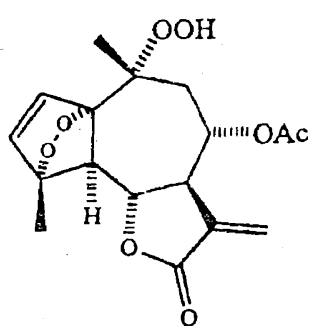

42

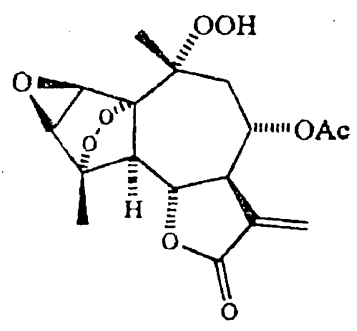

43

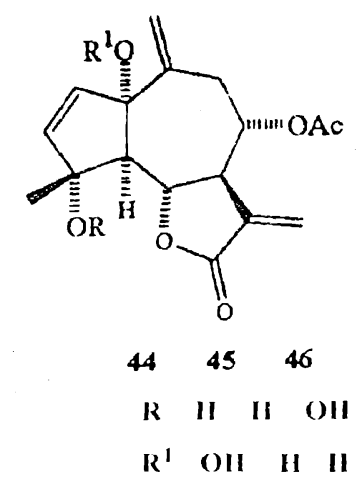

double bond was present. Most signals were close to those of one of the epimeric endoperoxides isolated from Tanacenm species ${ }^{38}$. However, these compounds had no 8-O-acetate group. When the shifis of $11-5$ and $11-6$ were compared with those of epimeric tanaparthin peroxides it was obvious that $\mathbf{4 2}$ was the $1 \alpha, 4 \alpha$-isomer. Noe difference spectroscopy gave clear effects between $\mathrm{H}-14$ and $\mathrm{H}-2$ and $\mathrm{H}-9 \alpha$, between $\mathrm{H}-5$ and $\mathrm{H}-7$, between $\mathrm{H}-6$ and $\mathrm{H}-\mathrm{S}$ and between $\mathrm{H}-15$, and $\mathrm{H}-3$ and $\mathrm{H}-5$, which established the proposed configurations. Models indicated however. that the orientation of $11-15$ cannot be assigned from these results. As the configuration of the isomcric endoperoxides from the Tanacetum species was established. the configuration at $\mathrm{C}-4$ in $\mathbf{4 2}$ was clear. The spectrum of 43 was in part similar to that of $\mathbf{4 2}$. However, the oletinic signals were replaced by a pair of upfield shifted doublets which were due to epoxide protons. The $\beta$-orientation of the epoxide oxygen caused a downfield shift of the H-6 signal. Further, clear noe were observed between $\mathrm{H}-5$ and $\mathrm{H}-7$, between $\mathrm{H}$ 6 and $\mathrm{H}-8$, between $\mathrm{H}-15$ and $\mathrm{H}-3$ as well as between $\mathrm{H}-14$ and $\mathrm{H}-9 \alpha$ and $\mathrm{H}-9 \beta$. Inspection of models indicaled that these effects required the proposed stereochemistry, while the couplings observed showed that the conformations of $\mathbf{4 2}$ and $\mathbf{4 3}$ were slightly different. Compound $\mathbf{4 2}$ was named as bishopantholide while 4.3 corresponding $2 \beta, 3,3$-epoxybishopantholide. The 'HNMR spectra of 44 and 46 were again in part very similar. Both compounds were transformed by reduction with tripheny/phosphine to the lactone 45 which was also present in the extract. The 'II NMR spectrum of 
$\mathbf{4 5}$ differed from that of $\mathbf{4 2}$ by the presence of exomethylene proton signals. As the $\mathrm{H}-9$ signals were shifted downfield, a 10 (14) - double bond was proposed. Compound 44 showed clear noe between $\mathrm{H}-6$ and $\mathrm{H}-8$, between $\mathrm{H}-15$ and H-6 and $\mathrm{H}-3$, between $\mathrm{H}-14$ and $\mathrm{H}-2$ and between $\mathrm{H}-14^{\prime}$ and $H-9 \alpha$. These results required the proposed configuration for 44-46 and the relative position of the hydroperoxide groups followed from the downfield shift of $\mathrm{H}-5$ in the spectrum of $\mathbf{4 6}$ if compared with that of 44 and 45 . The lactone without an oxygen function at $\mathrm{C}-1$ and $\mathrm{C}-4$ was named bishopsolicepolide and consequently 44-46 were characterized as $1 \alpha$-peroxy- $4 \alpha$-hydroxybishopsolicepolide, $1 \alpha, 4 \alpha$-dihydroxybishopsolicepolide and $1 \alpha$-hydroxy- $4 \alpha$ peroxy bishopsolicepolide, respectively.

So far two species of Blainvillea (Compositae, tribeHeliantheae, subtribe-Ecliptinae) have been examined chemically and both gave melampolides and some other sesquiterpene lactones ${ }^{39.40}$. The aerial parts of Blainvillea latifolia afforded zoapatanolides A and B, subacaulin 47 and a new guaianolide $\mathbf{4 8}$.

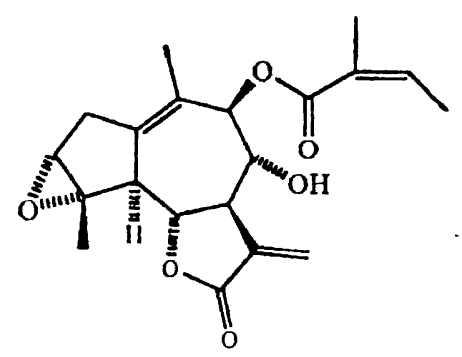

47

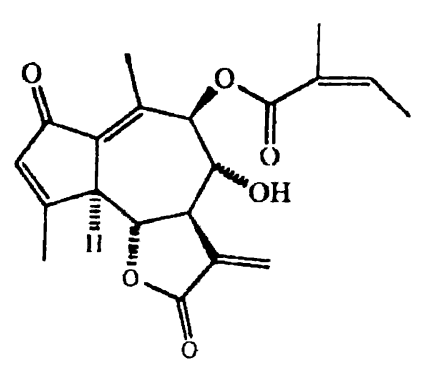

48

The structure of 48 could easily be deduced from the ${ }^{1} \mathrm{H}$ NMR spectrum which was close to that of dehydroleucodin ${ }^{41}$ and in part to that of $\mathbf{4 7 2}$. The configuration at C-8 and C9 followed from the observed couplings and the relative position of the ester group from the chemical shifts of $\mathrm{H}-8$ and H-9. From spectral data it was characterized as 5desoxypumilin.

\section{Acknowledgement}

The authors thank Dr. J Jakupovic and (Late) Prof. F.
Bohlmann, Berlin, Germany, for helpful suggestions and recording high field ' $\mathrm{H}$ NMR, high resolution mass and noe spectra. One of the authors (P.K.G. ) is grateful to C.S.I.R., New Delhi, for Junior Research Fellowship.

\section{References}

1. F Bohlmann, P Singh. N. Borthakur and J Jakupovic, Phytochemtstry, 1981, 30, 3379.

2 F Bohlmann, P. Singh, R M. King and H. Robinson, Phytochemistry, 1982, 21, 1171

3 F Bohlmann, P Singh and J. Jakupovic, Phytochemıstry, 1982, 21, 2029

4 F. Bohlmann and P. Singh, Phytochemistry, 1982, 21, 2119.

5 F. Bohlmann, P. Singh, J. Jakupovic and S. Huneck, Planta . Medica, 1984, 74.

6 P Singh and $M$ Bhala, Phytochemistry, 1988, 27, 1203

7 P. Singh, J Jakupovic, F. Bohlmann, R. M. King and H Robinson, Phytochemustry, 1985, 24, 2110.

8 P Singh, M. Bhala, R Jain and J Jakupovic, Phytochemistry, 1988, 27, 609 .

9. F Bohlmann. J Jakupovic, R K. Gupta, R. M. King and H Robinson, Phytochemistry, 1981, 20, 473.

10. Z. H. Abdel-Baset, L. Southwide, W G. Padolina, H. Yoshoka, T. J. Mabry and S. B Jones, Phytochemistry, 1971, 10, 2201

11 N. H. Fischer, E. J. Oliver and H D Fisher, Prog. Chem. Org. Natural Prod., 1979, 38, 47

12. H. Robinson, F Bohlmann and R. M King Phytologie, 1980, 46, 421

13 F Bohlmann, C. Zdero, R M. King and H. Robinson, Phytochemistry, 1980, 19, 2669

14. A. G. Gonzales, J. Bermejo, G. M. Massanet and J. Perez,An. Quin., 1973, 1333.

15. A. G. Gonzales, J. Bermejo, I. Cabrera, G. M. Massanet, H. Mansilla and A. Galindo, Phytochemistry, 1978, 17, 955.

$16 \mathrm{M}$ Suchy, V. Herout and F Sorm, Collect. Czech. Chem. Commun. 1959, 24, 1542.

17 F Bohlmann and N. Le Van, Phytochemistry, 1978, 17, 570.

18 F. Bohlmann, P. Singh and J Jakupovic, Phytochemustry, 1982, 21. 2122

19 F Bohlmann, C. Zdero, R M King and H. Robinson, Phytochemistry. 1979, 18, 1343

20 A. Gonzales, J Bermejo, G. M Massanet, J. H. Amaro and B Dominguez., Phytochemistry, 1976. 15, 991

21 F Bohlmann and R Bohlmann, Phytochemistry, 1980, 19, 2045.

22. F. Bohlmann, J. Jakupovic, W. R Abraham and C. Zdero, Phytochemistry, 1981. 20, 2371

23. M Dittrich, "The Biology and Chemistry of the Compositae," eds. V. N. lleywood, J B Harborne and B' L. Turner, Academic. London.

24 F Bohlmann, $T$ Burkhardt and C Zdero, "Naturally Occurring Acctylenes", Academic, London, 1973. 
Krishna et al. : Highly oxygenated guaianolides from some compositae plants

25. S. Das, R. N. Baruah, R. P. Sharma, J. N. Baruah, P. Kulanthaivel and W. Herz, Phytochemistry, 1983, 22, 1989.

26. S. V. Govindan and S. C. Bhattacharyya, Indian J. Chem., Sect. B. 1977, 956 .

27. P. V. Chugunov, K. S. Rybalko and A. I. Shreter. Khim. Prir: Soedin, 1971, 7, 727.

28. I. Shamyanov, N. D. Abdullacv, G. P. Sidyakin and K. Taizhanov, Khim. Prir. Soedin, 1981, 17, 667

29. P. S. Kalsi, S. Sharma and G. Kaur, Phytochemistry, 1983, 22. 1993.

30. O. A. Konovalova, K. S. Rybalko and M. G. Pimenov, Khim. Prir. Soedin, 1979, 15, 865.

31. N. V. Agafonova, L. E. Kushmir, A. D. Kuzovkov, A. I. Shreter and M. G. Pimenov, Aptechn. Delo, 1966, 15, 36.

32. S. B. Mathur, S. V. Hiremath, G. H. Kulkarni, G. R. Kalkar and S. C. Bhattacharyya, Tetrahedron, 1965, 21, 3575.
33. A. Rustaiyan, L. Nazarians and F. Bohlmann, Phytochemistry. 1981, 20, 1152 .

34. F. Bohlmann, D. Mahammadi and I. Jakupovic, Planta Med., 1984, 50, 192.

35. A. Ortega and E. Maldonado, Phytochemistry, 1984, 23, 1507.

36. A. Rustaiyan, Z. Sharif. A. Tajarodi. J. Ziesche and F. Bohlmann, Planta Med., 1984, 193.

37. H. Robinson, Phytologie, 1983, 54, 62

38. F. Bohlmann and C. Zdero, Phytochemistry, 1982, $21,2543$.

39. P. Singh, A. K. Sharma, K. C. Joshi, J. Jakupovic and F. Bohlmann, Phytochemistry, 1985, 24, 2023

40. F. Bohlmann, J. Ziesche, R. M. King and H. Robinson, Phytochemistry, 1981, 20, 263.

41. F. Bohlmann and C. Zdero, Tertrahedron Lett., 1972, 621.

42. W. Herz, S. V. Bhat and A. Srinivasan, J. Org. Chem., 1972, 37. 253. 
